\title{
Preparation of a new animal glue binder for foundry use
}

\author{
*Wei-hua Liu, Tian-shu Wang, Ying-min Li, Yu-yan Ren, and Wen-hui Huo \\ School of Materials Science and Engineering, Shenyang University of Technology, Shenyang 110870, China
}

\begin{abstract}
A new casting binder was prepared based on an animal bone glue. In order to overcome the disadvantages of the animal glue agglomeration at room temperature, an alkaline decomposition process was used, with acrylic acid, ammonium persulfate, and glucose as modifiers of the animal glue to obtain a high strength of binding. In the process of alkaline decomposition, $\mathrm{NaOH}$ was used as the catalyst with the addition of $3,4,5,6,7$, $8 \mathrm{wt} . \%$, respectively, into $100 \mathrm{~g}$ of animal glue and the alkaline decomposition temperature was set for $30,40,50,60$, and $70^{\circ} \mathrm{C}$, with an identical decomposition time of $30 \mathrm{~min}$, in order to reduce viscosity of the animal glue and maintain a liquid state at room temperature. The added acrylic acid, ammonium persulfate and glucose were determined through an orthogonal experiment. The experimental results are as follows: the optimal amount of $\mathrm{NaOH}$ addition is $5 \mathrm{wt} . \%$; alkaline decomposition temperature is $50^{\circ} \mathrm{C}$; the optimal weight ratio of three kinds of modifiers to animal glue is acrylic acid : ammonium persulfate : glucose : animal glue $=30: 3: 15: 100$; the modification reaction should be performed at $75^{\circ} \mathrm{C}$ with a reaction time of $90 \mathrm{~min}$. With the addition of $3 \%$ binder to sand, a final tensile strength of about 3.36 MPa and surface tension value of about $25.387 \mathrm{mN} \cdot \mathrm{m}^{-1}$ are achieved; the gas evolution at $850{ }^{\circ} \mathrm{C}$ is $19 \mathrm{ml} \cdot \mathrm{g}^{-1}$ and the residual strength after high temperature $\left(700^{\circ} \mathrm{C} \times 10 \mathrm{~min}\right)$ is $0 \mathrm{MPa}$. Finally, the new binder was characterized and analyzed by means of element analysis and an IR infrared spectrum.
\end{abstract}

Key words: animal glue; alkaline decomposition; modification; graft copolymerization; etherification; cross-linking

CLC numbers: TG223 Document code:A Article ID: 1672-6421(2016)04-238-05

$\mathrm{R}^{\mathrm{c}}$ ecently, environmental requirements of foundry production have become more and more strict. It is very important to prepare binders used in foundry with no environmental pollution. Animal glue, as a nontoxic, biodegradable natural polymer material has a good environmental performance ${ }^{[1]}$. Using it as a foundry binder is a very interesting topic, and many scholars have already carried out relevant research. J. S. Siak et al. first proposed and prepared the GMBOND binder, which was successfully applied in the production of aluminum alloy automobile cylinder heads/blocks ${ }^{[2]}$. Jing-yu Shi used an animal glue as a core sand binder, and made a systematic study on the casting process and regeneration method of the bonded core sand ${ }^{[3]}$. We prepared a new modified animal glue binder and the bonded sand mold/core displayed a higher compressive strength hardened by

\footnotetext{
*Wei-hua Liu

Male, born in 1968, associate professor, doctor. His reseach mainly focuses on foundry materials.

E-mail: 974942647@ qq.com
}

Received: 2016-03-04; Accepted: 2016-06-01
$\mathrm{CO}_{2}{ }^{[4]}$.

In this study, three modifiers (acrylic acid, ammonium persulfate and glucose) were used to prepare a new animal glue binder with a low surface tension and high tensile strength. The new modified animal binder was characterized and analyzed by means of IR infrared spectrometer and element analysis. The mechanism of animal glue modification was also discussed.

\section{Experimental procedures}

\subsection{Materials}

The main raw materials used included animal glue, sodium hydroxide, acrylic acid, glucose, ammonium persulfate, anticoagulant, and "ZGS-50/100(60)" standard sand from Dalin, China.

\subsection{Preparation of animal glue binder}

In a 1000-ml three-neck flask, at room temperature, the animal glue and water with a proportion of 5:8 (by weight) was mixed, and the mixing process was taken for $30 \mathrm{~min}$ to allow the animal glue to fully dissolve and swell in the water. Then, 3, 4, 5, 6, 7, 8wt. $\% \mathrm{NaOH}$ as 
the catalyst was added respectively to the mixture to decompose the animal glue. After that, the acrylic acid, ammonium persulfate and glucose were added. After 60 to 120 minutes of reaction, an anticoagulant was added, and the mixture was stirred for another 30 minutes, and cooled to room temperature. Finally, a brown liquid animal glue binder was obtained. The animal glue binder with no modifier was also prepared for comparison.

\subsection{Orthogonal experiment}

An orthogonal experimentation was used to determine the optimal addition amount of each modifier. Tensile strength of sand sample was tested as an important property index of the binder. The orthogonal experiment of L9(33), which contains factors with three levels of amount of each modifiers, was designed as Table 1, and the test scheme was arranged as Table 2.

Table 1: Design of orthogonal factors and levels

\begin{tabular}{|cccc|} 
Level & Acrylic acid (g) & $\begin{array}{c}\text { Ammonium } \\
\text { persulfate (g) }\end{array}$ & Glucose (g) \\
\hline 1 & 24 & 2.0 & 10 \\
2 & 30 & 3.0 & 15 \\
3 & 36 & 4.0 & 20 \\
\hline
\end{tabular}

Table 2: Test scheme

Test No. Acrylic acid Ammonium persulfate Glucose

$\begin{array}{llll}1 & \text { A1 } & \text { B1 } & \text { C1 } \\ 2 & \text { A1 } & \text { B2 } & \text { C2 } \\ 3 & \text { A1 } & \text { B3 } & \text { C3 } \\ 4 & \text { A2 } & \text { B1 } & \text { C2 } \\ 5 & \text { A2 } & \text { B2 } & \text { C3 } \\ 6 & \text { A2 } & \text { B3 } & \text { C1 } \\ 7 & \text { A3 } & \text { B1 } & \text { C3 } \\ 8 & \text { A3 } & \text { B2 } & \text { C1 } \\ 9 & \text { A3 } & \text { B3 } & \text { C2 }\end{array}$

\subsection{Preparation of sand samples}

At first, $1000 \mathrm{~g}$ of standard sand was mixed with $30 \mathrm{~g}$ binder for $120 \mathrm{~s}$, then the standard "dog bone" samples were prepared using the sand mixture. The prepared samples were baked at about $180^{\circ} \mathrm{C}$ in an oven. After 20 min sintering, samples were taken out and cooled to room temperature ready for the test.

The tensile strength of the sand samples was measured on a "SWY" tensile strength testing machine, and the final tensile strength after $24 \mathrm{~h}$ was used as the main technological parameter.

The surface tension value of the animal glue binder was determined using the "Sigma700" surface tension meter. After being dried sufficiently, the structures of two kinds of animal glue binders, with and without modification, were analyzed using an IR Prestige-21 Fourier infrared spectrometer.

\section{Results and discussion}

\subsection{Determination of alkaline hydrolysis process}

Animal glue is a macromolecule compound and it easily agglomerates at room temperature, which makes it very difficult to be directly used in a foundry. By catalytic decomposition, the -NH-CO- peptide molecular structure of the animal glue can be decomposed to a smaller molecular structure, which is liquid at room temperature and apt to chemical reaction. Surface tension is one of the most important parameters to describe the wetability of liquid, and reduction of the surface tension is mainly determined by a better wetting performance between the binder and the sand.

Figure 1 shows the influence of different amounts of $\mathrm{NaOH}$ on the surface tension value of the animal glue binder and tensile strength of sand samples.

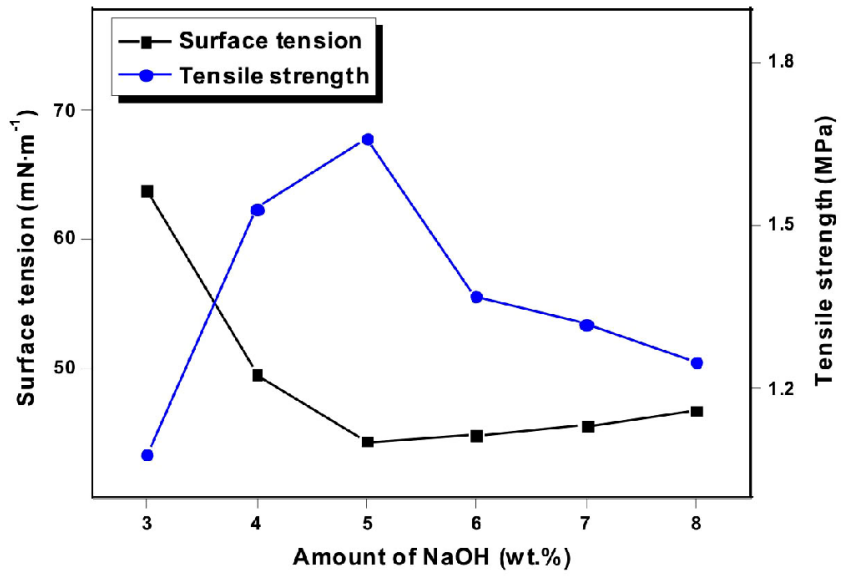

Fig. 1: Effect of different amounts of $\mathrm{NaOH}$ on the surface tension value of animal glue binder and the tensile strength of sand samples

When the amount of added $\mathrm{NaOH}$ was less than 5wt.\%, with an increase in the amount of $\mathrm{NaOH}$, the surface tension value of animal glue binder rapidly decreased and the tensile strength of sand samples increased. When the addition amount is more than $5 \mathrm{wt} . \%$, with an increase in the amount of $\mathrm{NaOH}$, the tensile strength of sand samples decreased, the surface tension value increased slowly, so the optimal addtion amount of $\mathrm{NaOH}$ is about 5 wt. $\%$.

In order to determine the optimal alkaline decomposition temperature, a 30 min alkaline decomposition time was selected, and the influence of different alkaline decomposition temperatures on the tensile strength of sand samples was studied, with results shown in Fig. 2.

The results show that the tensile strength reached the highest peak at $50^{\circ} \mathrm{C}$, so the alkaline decomposition temperature was selected at $50{ }^{\circ} \mathrm{C}$. After alkaline decomposition, the viscosity of the animal glue binder was about $700 \mathrm{mPa} \bullet \mathrm{s}$ at $25^{\circ} \mathrm{C}$. 


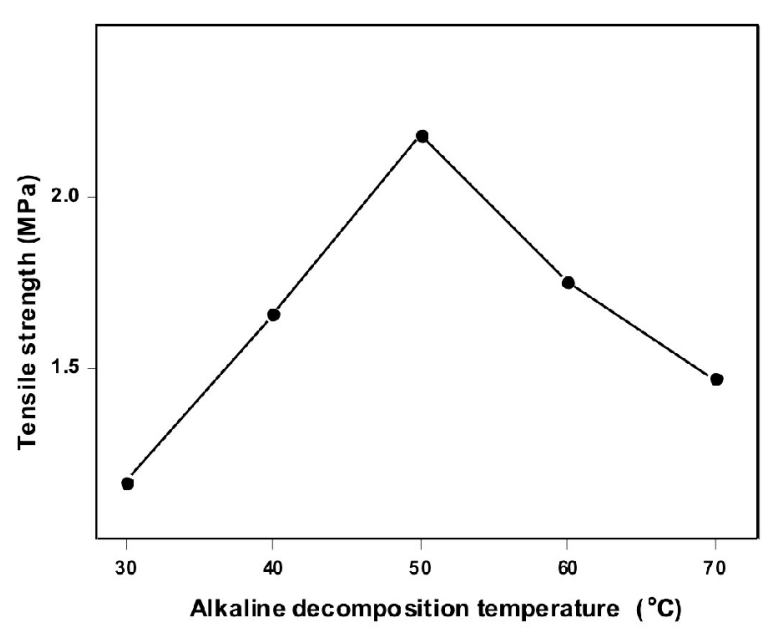

Fig. 2: Effect of alkaline decomposition temperature on tensile strength of sand sample

\subsection{Design of composite modification and orthogonal test}

Animal glue is a macromolecular compound that consists of many multiple amino acid molecules linked by peptide bond. After alkaline decomposition, some peptide bond structures among the glue molecules may be decomposed into amidogens and carboxyls.

Analysis showed that in three kinds of modifiers selected in the present study, some cross-linking reactions such as copolymerization and esterification etc. could occur.

Acrylic acid is a typical monomer, and the polyacrylic acid can be polymerized with the ammonium persulfate as initiator (equation 1), and then an amidation reaction can occur between the $(-\mathrm{COOH})$ in polyacrylic acid and amino $\left(-\mathrm{NH}_{2}\right)$ in the animal glue (equation 2). The esterification cross-linking can take place between hydroxyl $(-\mathrm{OH})$ of glucose and carboxyl $(-\mathrm{COOH})$ of animal glue (equation 3 ). The equations are as follows:<smiles>C=CC(=O)OCCCCC(C)C(=O)O</smiles>

(equation 1)

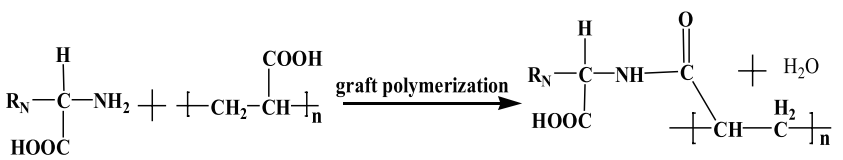

(equation 2)

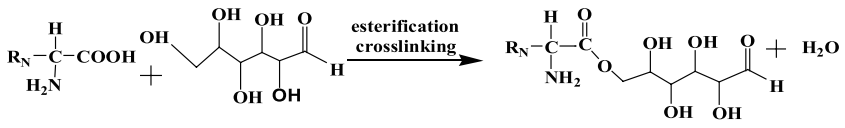

(equation 3)

In order to evaluate the effect of three factors on the performance of animal glue binder and find the main factors and optimization scheme, the range analysis of orthogonal experiment results was carried out, and the results are shown in Table 3 and Fig. 3.
It can be seen from Fig. 3 that the optimal combination of three modifiers was $\mathrm{A}_{2} \mathrm{~B}_{2} \mathrm{C}_{2}$, and the optimal ratio of the modifiers to animal glue by weight was determined as acrylic acid: ammonium persulfate : glucose: animal glue $=$ 30:3:15:100.

By verification test of orthogonal results, the tensile strength of the sand sample was $3.36 \mathrm{MPa}$ and the binder surface tension value was $25.387 \mathrm{mN} \cdot \mathrm{m}^{-1}$.

Table 3: Result and analysis of orthogonal experiment

\begin{tabular}{|c|c|c|c|c|}
\hline Test No. & $\begin{array}{c}\text { Acrylic } \\
\text { acid }\end{array}$ & $\begin{array}{c}\text { Ammonium } \\
\text { persulfate }\end{array}$ & Glucose & $\begin{array}{l}\text { Tensile strength } \\
\text { (MPa) }\end{array}$ \\
\hline 1 & $\mathrm{~A} 1$ & B1 & C1 & 3.18 \\
\hline 2 & $\mathrm{~A} 1$ & B2 & $\mathrm{C} 2$ & 2.71 \\
\hline 3 & A1 & B3 & $\mathrm{C} 3$ & 2.29 \\
\hline 4 & $\mathrm{~A} 2$ & B1 & $\mathrm{C} 2$ & 2.94 \\
\hline 5 & $\mathrm{~A} 2$ & B2 & C3 & 3.29 \\
\hline 6 & $\mathrm{~A} 2$ & B3 & $\mathrm{C} 1$ & 3.01 \\
\hline 7 & A3 & B1 & C3 & 2.39 \\
\hline 8 & A3 & B2 & C1 & 2.57 \\
\hline 9 & A3 & B3 & $\mathrm{C} 2$ & 3.22 \\
\hline $\mathrm{k} 1$ & 2.73 & 2.84 & 2.92 & \\
\hline k2 & 3.08 & 2.86 & 2.96 & \\
\hline k3 & 2.73 & 2.84 & 2.60 & \\
\hline $\mathrm{R}$ & 0.35 & 0.02 & 0.36 & \\
\hline
\end{tabular}

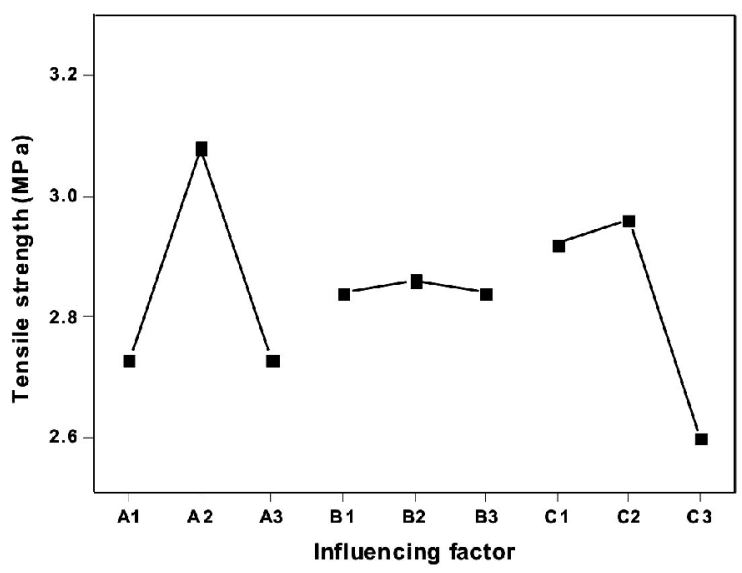

Fig. 3: Range analysis of orthogonal experiment results

\subsection{Optimization of modification process}

While other conditions remained the same, the influences of modification temperature on the tensile strength and surface tension of the animal glue binder were shown in Fig. 4.

As can be seen in Fig. 4, the tensile strength increased firstly with an increase in the reaction temperature, and reached the peak at $75{ }^{\circ} \mathrm{C}$, and then declined sharply; while the surface tension of the animal glue binder slowly decreased to the minimum value at $75^{\circ} \mathrm{C}$, and then increased rapidly. Therefore, the modification reaction performed at $75^{\circ} \mathrm{C}$ should be appropriate. 


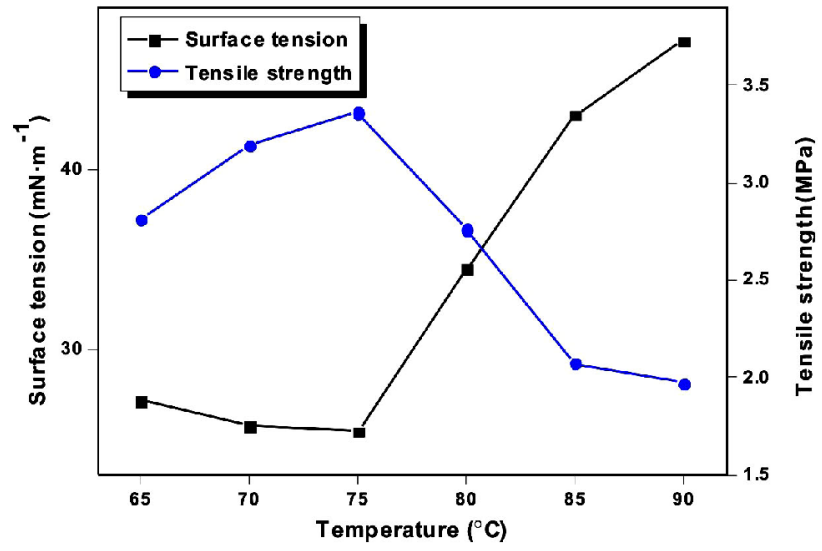

Fig. 4: Effect of modification reaction temperature on tensile strength and surface tension of animal glue binder

The influence of modification time on the binder was tested and shown in Fig. 5.

With prolonging the modification reaction time, the tensile strength increased and reached a peak strength at the $90 \mathrm{~min}$, while the surface tension value of the binder was just at valley bottom on opposite. Therefore, the reaction time of $90 \mathrm{~min}$ should be selected.

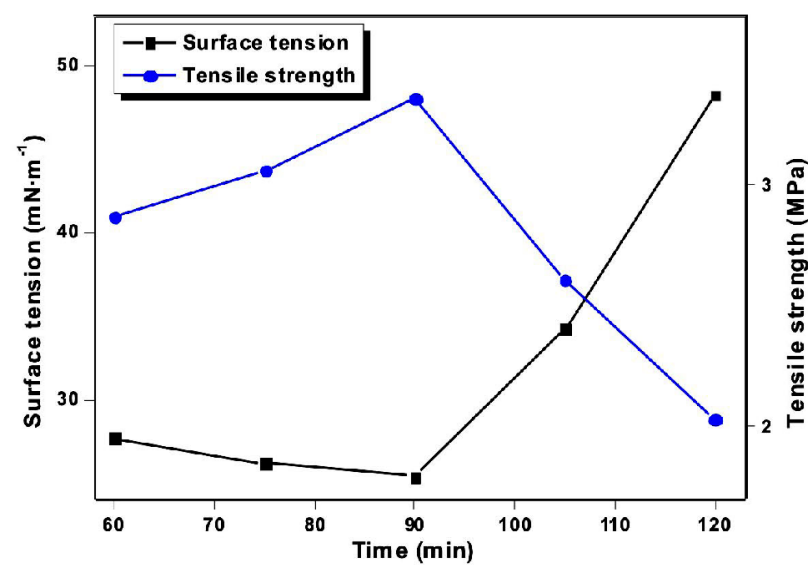

Fig. 5: Effect of modification reaction time on tensile strength and surface tension of animal glue binder

\subsection{Characterization results of animal glue binder}

Table 4 shows the result of elemental analysis of the animal glue binder. The main chemical elements in the animal glue binder are $\mathrm{C}, \mathrm{H}$ and $\mathrm{N}$, and no $\mathrm{S}$ and $\mathrm{P}$ was found. After the addition of modifiers, the contents of the main elements in the binder have a greater change than those of the binder with no modifiers.

The new animal glue binder was characterized and analyzed by means of IR infrared spectrum, and the results are shown in Fig. 6.

As can be seen in Fig. 6, the absorption peak of near 3,423 $\mathrm{cm}^{-1}$ changes sharply, showing that there could be a (-OH) bond. The obvious absorption peak near $1,543 \mathrm{~cm}^{-1}$ is a
Table 4: Analysis results of elements in animal glue binder

\begin{tabular}{ccc} 
Element & $\begin{array}{c}\text { Unmodified animal } \\
\text { glue }\end{array}$ & $\begin{array}{c}\text { Modified animal } \\
\text { glue }\end{array}$ \\
C & 39.67 & 40.43 \\
N & 13.88 & 10.90 \\
H & 6.14 & 5.93 \\
\hline
\end{tabular}

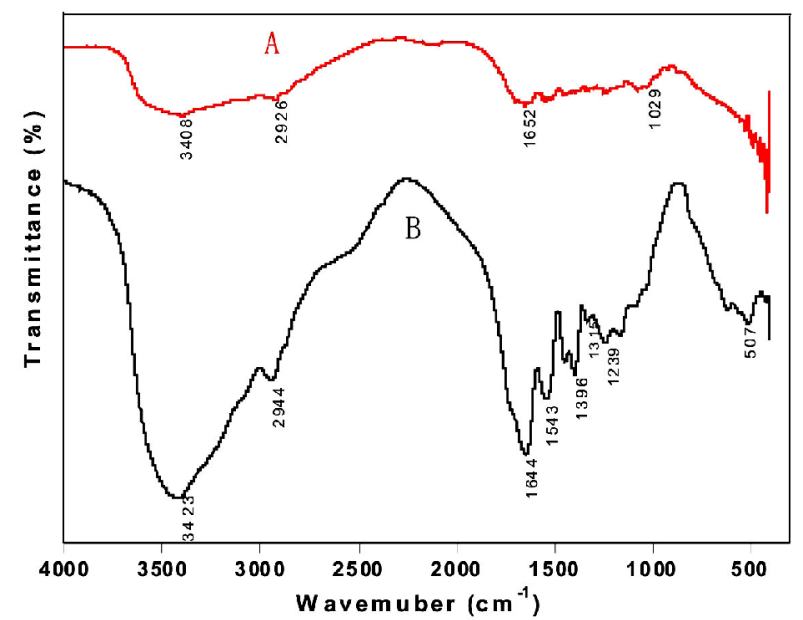

Fig. 6: IR infrared spectrum of animal glue binder ( $A$ is curve of unmodified animal glue binder, and $B$ is curve of modified animal glue binder)

secondary amine (-RNH) stretching vibration. The absorption peak near $1,315 \mathrm{~cm}^{-1}$ is a $\mathrm{C}-\mathrm{N}$ bond stretching vibration, which proved the existence of amide groups, indicating a reaction between the amino acid of animal glue and the carboxyl of acrylic acid modifier. The anti-symmetric stretching vibration peak near $1,239 \mathrm{~cm}^{-1}$ with a $\mathrm{C}-\mathrm{O}-\mathrm{C}$ bond, and the absorption peak near $1,644 \mathrm{~cm}^{-1}$ with a $-\mathrm{C}=\mathrm{O}$ bond, are the proof of the existence of carboxylic acid ester, indicating that an esterification reaction happens between the $-\mathrm{COOH}$ of the animal glue and the $-\mathrm{OH}$ of the glucose modifier.

\subsection{Animal glue binder sand performance}

After the sand samples were heated to three different temperatures for $10 \mathrm{~min}$ and cooled to room temperature, their residual strengths were tested. The results are shown in Table 5. It can be seen that the residual strength of sand samples after being heated at high temperature was very low, which means that the binder has a good collapsibility in the course of casting.

The gas evolution at a temperature of $850{ }^{\circ} \mathrm{C}$ was tested by means of a SFL gas evolution test apparatus with $(1 \pm 0.01) \mathrm{g}$ binder sand and the results are shown in Fig. 7. The gas evolution of the sand sample is about $19 \mathrm{ml} \cdot \mathrm{g}^{-1}$.

Table 5: Residual strength of sand samples after high temperature

\begin{tabular}{cccc} 
& Heating temperature & $\left.{ }^{\circ} \mathrm{C}\right)$ \\
& 500 & $\mathbf{6 0 0}$ & $\mathbf{7 0 0}$ \\
\hline Residual strength (MPa) & 0.39 & 0.08 & 0
\end{tabular}




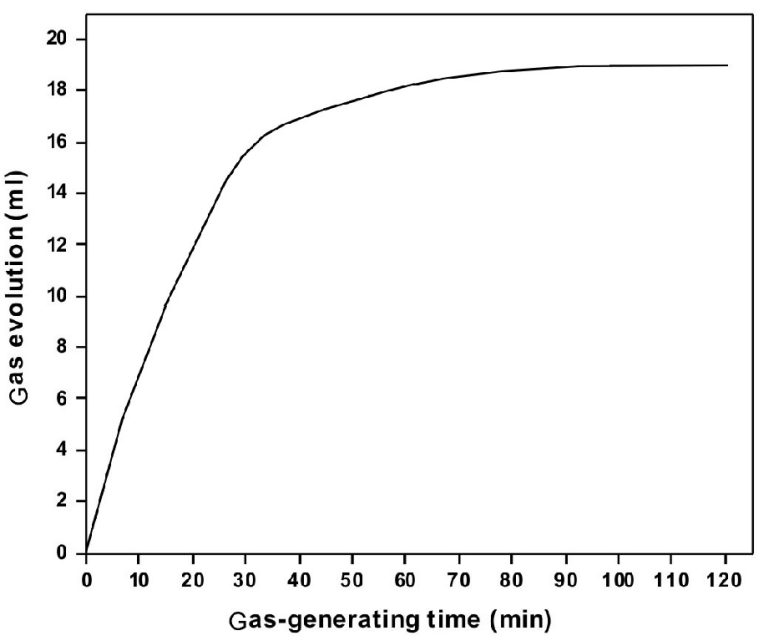

Fig. 7: Curve of gas evolution of sand sample

The influence of the addition amount of the animal glue on the tensile strength of sand samples was tested and results are shown in Fig. 8. When the animal glue binder content was 3.0\%, the highest tensile strength of $3.36 \mathrm{MPa}$ was obtained.

The effects of the storage time of the animal glue binder on its viscosity and tensile strength of the sand sample are shown in Table 6 . When the binder was stored for 60 days, the viscosity of the binder increased slightly and the tensile strength of sand sample decreased to $2.86 \mathrm{MPa}$, which would still meet the need of core-making.

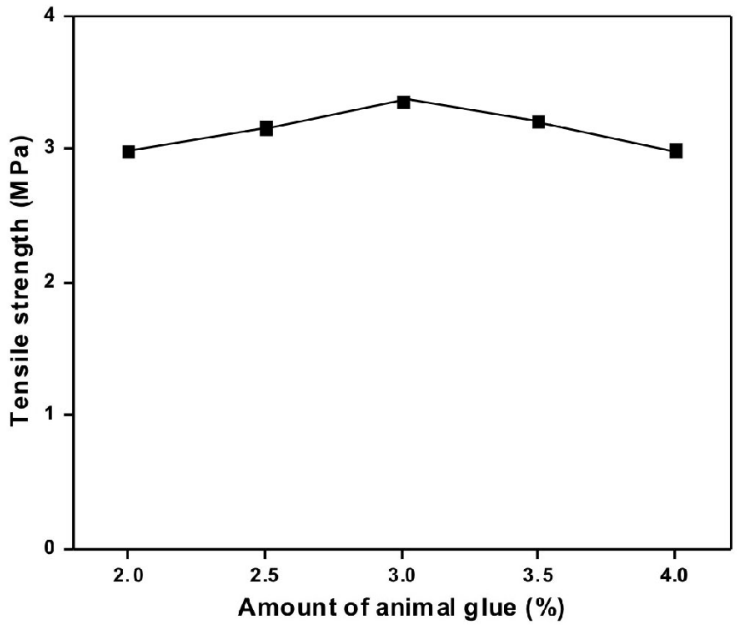

Fig. 8: Effect of binder addition amount on tensile strength of sand samples
Table 6: Effect of storage time of animal glue on its viscosity and tensile strength

\begin{tabular}{ccc}
$\begin{array}{c}\text { Storage time } \\
\text { (Day) }\end{array}$ & $\begin{array}{c}\text { Viscosity } \\
\text { (mPa•s) }\end{array}$ & $\begin{array}{c}\text { Tensile strength } \\
\text { (MPa) }\end{array}$ \\
\hline 20 & 960 & 3.15 \\
40 & 1020 & 3.08 \\
60 & 1100 & 2.86 \\
\hline
\end{tabular}

\section{Conclusions}

(1) A new animal glue binder which is liquid at room temperature can be prepared by alkali decomposition and modification with a low surface tension $\left(25.387 \mathrm{mN} \cdot \mathrm{m}^{-1}\right)$, and used for core sand with a higher tensile strength (3.36 MPa).

(2) $\mathrm{NaOH}$ can be used as the catalyst for the alkaline decomposition; the optimal amount of $\mathrm{NaOH}$ addition is $5 \mathrm{wt} . \%$; alkaline decomposition temperature is $50{ }^{\circ} \mathrm{C}$.

(3) The optimal weight ratio of three modifiers to animal glue is acrylic acid: ammonium persulfate: glucose : animal glue $=30: 3: 15: 100$; the appropriate temperature of modification reaction is $75^{\circ} \mathrm{C}$, and the reaction time is $90 \mathrm{~min}$.

(4) Element analysis showed that the new animal glue binder is neither noxious nor harmful. The IR infrared spectrum further proved that the structure of the binder had been changed after the alkaline decomposition and modification. Analysis showed that some cross-linking reactions such as copolymerization and esterification might occur during the modification process.

(5) An optimal addition amount of binder into the sand is $3.0 \mathrm{wt} . \%$; the gas evolution at $850{ }^{\circ} \mathrm{C}$ is $19 \mathrm{ml} \cdot \mathrm{g}^{-1}$; the residual strength after high temperature $\left(700{ }^{\circ} \mathrm{C} \times 10 \mathrm{~min}\right)$ is $0 \mathrm{MPa}$.

\section{References}

[1] Li Ai-ju and Chen Hong-yu. Development of environmentally friendly materials. Research and Application of Materials, 2010, 4(4): 372-378.

[2] Siak J S, Whited W, Schreck R, et al. Develops a breakthrough "green" binder for core sand. Modern Casting, 1996, 86(10): 24-26.

[3] Shi Jing-yu, He Zhen-ming, Wang qiang, et al. Making foundry mould and core binders by animal glue. Foundry Equipment and Technology, 2000(02): 20-22.

[4] Liu Wei-hua, Zhang Yi-lin, Li Ying-min, et al. Optimization of a new animal glue binder system cured by $\mathrm{CO}_{2}$ for foundry use. China Foundry, 2012, 9(4): 356-359. 